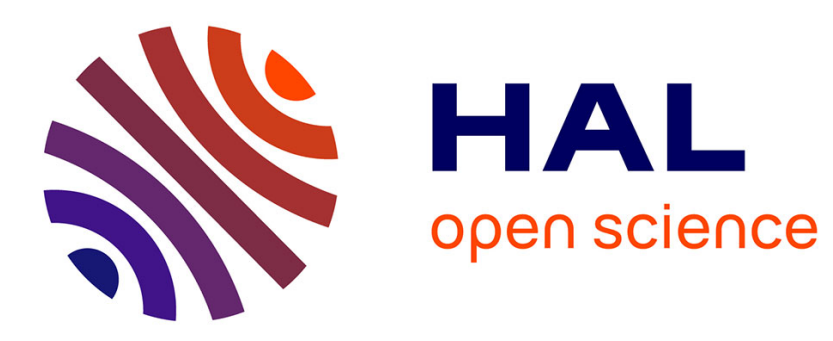

\title{
Influence of 24-epibrassinolide on lipid signalling and metabolism in Brassica napus
}

\author{
I. V Pokotylo, S. Kretynin, V. A Khripach, Eric Ruelland, Ya. Blume, S.
}

Kravets

\section{- To cite this version:}

I. V Pokotylo, S. Kretynin, V. A Khripach, Eric Ruelland, Ya. Blume, et al.. Influence of 24epibrassinolide on lipid signalling and metabolism in Brassica napus. Plant Growth Regulation, 2014, 73 (1), pp.9-17. 10.1007/s10725-013-9863-y . hal-02165173

\section{HAL Id: hal-02165173 \\ https://hal.science/hal-02165173}

Submitted on 25 Jun 2019

HAL is a multi-disciplinary open access archive for the deposit and dissemination of scientific research documents, whether they are published or not. The documents may come from teaching and research institutions in France or abroad, or from public or private research centers.
L'archive ouverte pluridisciplinaire HAL, est destinée au dépôt et à la diffusion de documents scientifiques de niveau recherche, publiés ou non, émanant des établissements d'enseignement et de recherche français ou étrangers, des laboratoires publics ou privés. 
archives-ouvertes

\section{Influence of 24-epibrassinolide on lipid signalling and metabolism in Brassica napus}

I. Pokotylo, S. Kretynin, V. Khripach, Eric Ruelland, Ya. Blume, S. Kravets

\section{To cite this version:}

I. Pokotylo, S. Kretynin, V. Khripach, Eric Ruelland, Ya. Blume, et al.. Influence of 24-epibrassinolide on lipid signalling and metabolism in Brassica napus. Plant Growth Regulation, Springer Verlag, 2014, 73 (1), pp.9-17. 10.1007/s10725-013-9863-y . hal-02165173

\section{HAL Id: hal-02165173 \\ https: / hal.archives-ouvertes.fr/hal-02165173}

Submitted on 25 Jun 2019

HAL is a multi-disciplinary open access archive for the deposit and dissemination of scientific research documents, whether they are published or not. The documents may come from teaching and research institutions in France or abroad, or from public or private research centers.
L'archive ouverte pluridisciplinaire HAL, est destinée au dépôt et à la diffusion de documents scientifiques de niveau recherche, publiés ou non, émanant des établissements d'enseignement et de recherche français ou étrangers, des laboratoires publics ou privés. 


\title{
Influence of 24-epibrassinolide on lipid signalling and metabolism in Brassica napus
}

\author{
I. V. Pokotylo $\cdot$ S. V. Kretynin • V. A. Khripach • \\ E. Ruelland $\cdot$ Ya. B. Blume $\cdot$ V. S. Kravets
}

\begin{abstract}
Due to the increasing demand for biofuel production, it is an important goal to optimize the seed productivity and quality of oilseed plants even in adverse conditions. Acting on signalling mechanisms might provide means to attain such goals. In this study, we were interested in the effect of a brassinosteroid hormone 24-epibrassinolide (24-EBR) on Brassica napus cultivated in salt stress condition. We show that salt stress leads to a $60 \%$ decrease in seed production in B. napus. This is accompanied by a $50 \%$ decrease in seed oil content. Treatment with 24-EBR had no effect on seed and oil productivity in control plants. However, it could rescue half of the seed production and all the oil production in salt-treated plants. The fatty acid composition of seed oil in B. napus was selectively affected by salt stress, 24-EBR or combined treatment. Besides these
\end{abstract}

Electronic supplementary material The online version of this article (doi:10.1007/s10725-013-9863-y) contains supplementary material, which is available to authorized users.

I. V. Pokotylo · S. V. Kretynin · V. S. Kravets $(\bowtie)$

Institute of Bioorganic Chemistry and Petrochemistry, National Academy of Sciences of Ukraine, Murmanska 1, Kiev 02660, Ukraine

e-mail: kravets@bpci.kiev.ua

V. A. Khripach

Institute of Bioorganic Chemistry, National Academy of

Sciences of Belarus, Kuprevicha 5/2, 220141 Minsk, Belarus

E. Ruelland

EAC7180, Physiologie Cellulaire et Moléculaire des Plantes, Centre National de la Recherche Scientifique, 4 Place Jussieu, 75005 Paris, France

Ya. B. Blume

Institute of Food Biotechnology and Genomics, National Academy of Sciences of Ukraine, Osypovskogo 2a, Kiev 04123, Ukraine long-term actions of 24-EBR, we have also investigated its short-term actions in cell signalling. We did so by in vivo labelling of plantlets with fluorescently labelled phosphatidylcholine. A treatment of $2 \mathrm{~h}$ with 24-EBR was sufficient to induce a substantial increase in the content of diacylglycerol and phosphatidic acid, two lipid mediators. Nonspecific phospholipases $\mathrm{C}$ and phospholipases $\mathrm{D}$ are involved in these increases. Therefore, brassinosteroid treatments appear as promising way to gain oil productivity when plants have to grow in unfavourable conditions such as salt stress. The link between long-term actions and shortterm signalling of 24-EBR is discussed.

Keywords 24-Epibrassinolide - Oil productivity · Salt stress · Fatty acids · Phospholipase D · Nonspecific phospholipase $\mathrm{C}$

\section{Introduction}

Plant oil is now considered as one of the main sources of biorenewable fuels. In the majority of plants, oil is stored in seeds as triacylglycerols (TAG) that will serve as an energy reserve required for the initial growth of seedlings in the absence of established photosynthesis. In plants, TAG biosynthesis pathway is known to be complex (Fig. 1). All fatty acids (FA) initially originate from a pool of acetylcoenzyme A (CoA) that is located in the plastids. Then, plastid-localized and endoplasmic reticulum-localized enzymes participate in the biosynthesis of all main cell glycerolipids, including storage TAGs (Voelker and Kinney 2001; Chapman and Ohlrogge 2012). Glycerol-3-phosphate acyltransferase (GPAT), lysophosphatidic-acid acyltransferase (LPAAT) and diacylglycerol acyltransferase (DGAT), that catalyse the consecutive acylation steps of the 


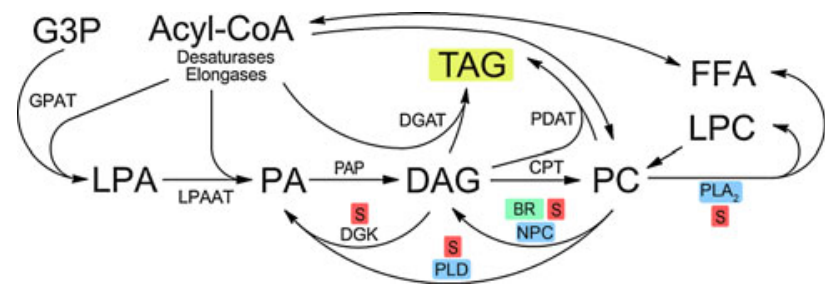

Fig. 1 Simplified scheme of plant TAG biosynthesis pathways. Metabolic steps affected by salt stress (S), brassinosteroids (BR) or controlled by phospholipase activity are highlighted (Kocourková et al. 2011; Wimalasekera et al. 2010; Pokotylo et al. 2012). DAG, diacylglycerol; DGAT, DAG acyltransferase; DGK, diacylglycerol kinase; G3P, glycerol 3-phosphate; FFA, free fatty acids; G3P, glycerol 3-phosphate; GPAT, glycerol-3-phosphate acyltransferase; LPA, lysophosphatidic acid; LPC, lysophosphatidylcholine; LPAAT, lysophosphatidic acid acyltransferase; PA, phosphatidic acid; PAP, phosphatidic acid phosphohydrolase; PC, phosphatidylcholine; PLD, phospholipase D; NPC, non-specific phospholipase C; $\mathrm{PLA}_{2}$, phospholipase A2; TAG, triacylglycerol; CPT, choline phosphotransferase; PDAT, phospholipid:diacylglycerol acyltransferase

glycerol-3-phosphate backbone, are all critical for TAG biosynthesis. Alternatively, the $s n-3$ acylation of DAG can be achieved by the combined actions of plant-specific choline phosphotransferases (CPT) and phospholipid:diacylglycerol acyltransferases (PDAT). Most of these pathways have been characterized both at biochemical and molecular levels (Beisson et al. 2003). Yet, how plants achieve an efficient metabolic biosynthesis in adverse conditions is not entirely understood.

Nevertheless, there have been numbers of attempts to develop crop plants with improved oil yield or providing oils with specific FA composition. Several biotechnological approaches were implemented including genetic engineering aimed at manipulating the lipid/FA biosynthesis pathways (Tan et al. 2011; Ruiz-López et al. 2012; Bates and Browse 2012). However, it is becoming clearer and clearer that oil productivity is a complex trait controlled by several enzymatic complexes (Tang et al. 2012). That is why affecting individual enzymes in lipid biosynthesis pathways may not be as effective as originally expected (Ohlrogge and Jaworski 1997). In contrast, treatments of plant with hormones, that orchestrate plant development and influence major metabolic fluxes, might be a promising way of modulating oil quantity and quality in seeds. Indeed, synthetic cytokinins were shown to affect oil accumulation in Lavandula dentata plantlets (Sudriá et al. 2001) and rhizobacteria-derived auxins increased the oil quantity in Brassica juncea (Asghar et al. 2002). Brassinosteroids (BRs) constitute a unique group of plant steroid growth-promoting hormones that, at low concentrations, act as important metabolism regulators (Kim and Wang 2010). BRs, that include 24-epibrassinolide (24-EBR), are sensed by BRASSINOSTEROID-INSENSITIVE 1 receptor kinase and activate distinct signal transduction cascade and cellular responses (Clouse 2011). Receptor-independent effects of lipophilic BRs on plant metabolism and plant membranes have also been suggested (Albrecht et al. 2011; Zhang et al. 2005). BRs stimulate plant growth and photosynthesis (Xia et al. 2009) and affect activity of antioxidant systems (Zhang et al. 2010). BRs can also increase plant stress tolerance (Divi et al. 2010) and improve B. napus germination and growth in drought and saline conditions (Kagale et al. 2007). The role of BRs in stomata development has also been demonstrated (Kim et al. 2012) and may be crucial for water-use efficiency in salt-stressed plants. However, the exact mechanisms of BR-induced plant regulation are unclear.

The intracellular action of BRs may be functionally associated with phospholipases that control many plant growth reactions (Wang et al. 2012). Phospholipases hydrolyse membrane lipids to produce second messengers essential for regulatory signalling. Phospholipases also contribute to generic lipid metabolism and lipid turnover (Li et al. 2006) including TAG biosynthesis (Lee et al. 2011). In addition, phospholipases are well known to participate in stress and hormone signalling (Janda et al. 2013). As an example, phosphatidic acid (PA) production via phospholipase D activity was rapidly induced in saltstressed tobacco (Pokotylo et al. 2012) while overexpression of phospholipase $\mathrm{D} \alpha$ resulted in improved drought and salt tolerance of plants (Peng et al. 2010; Zhang et al. 2008). Interestingly, plant non-specific phospholipases $C$ (NPC), which are able to directly cleave structural membrane phospholipids to produce diacylglycerol (DAG) (Pokotylo et al. 2013), were activated after BR treatment in tobacco BY-2 cells (Wimalasekera et al. 2010).

Therefore, the aim of this study was to investigate the influence of 24-EBR on oil productivity and fatty acid composition of seed oil from B. napus plants subjected to salt stress. The role of phospholipases in mediating BR effects is also analysed.

\section{Materials and methods}

Plant material and treatments

Brassica napus cv. Magnat plants and Arabidopsis thaliana Col-1 plants were used in this study. Seeds were imbibed and cold treated at $4{ }^{\circ} \mathrm{C}$ for 4 days before germination and growth. B. napus plants used in cultivation experiments were grown open-air in isolated vessels in alfisol-type soil subjected to temperate climate conditions with controlled watering. Arabidopsis plants were grown in soil under long day conditions (16 h light $125 \mu \mathrm{E} \mathrm{m}^{-2} \mathrm{~s}^{-1} ; 8 \mathrm{~h}$ dark) at $23{ }^{\circ} \mathrm{C}$. Salt stress was induced by watering with $0.5 \mathrm{M}$ $\mathrm{NaCl}$ solution to achieve final concentration of $50 \mathrm{mM}$ 
$\mathrm{NaCl}$ in the soil. Chemically synthesized 24-epibrassinolide was obtained from the Institute of Bioorganic Chemistry of the National academy of Sciences of Belarus (Khripach 1990). Leaves of B. napus plants were sprayed with $0.1 \mu \mathrm{M}$ solution of 24-EBR twice during the course of cultivation.

Brassica napus plants used in short-term signalling experiments were grown hydroponically in half-strength MS solution. $N$-ethylmaleimide and $n$-butanol were used at final concentrations of $5 \mathrm{mM}$ and $0.5 \%$ (v/v), respectively.

Analysis of seed oil content and FA composition

Total seed oil was extracted by the addition of $10 \mathrm{ml}$ of hexane to $500 \mathrm{mg}$ of freshly ground seeds followed by vacuum evaporation. FA composition of lipid samples was assessed by HPLC analysis using the method described by Chaytor (1987) with modifications. In brief, lipids were saponificated with butylated hydroxytoluene in $1 \mathrm{M}$ solution of $\mathrm{KOH}$ in methanol over a period of $1 \mathrm{~h}$ at $80-90{ }^{\circ} \mathrm{C}$. The solution thus obtained was diluted with tetrahydrofuran or acetonitrile and neutralized with $1 \mathrm{M}$ orthophosphoric acid. Then, $0.2 \mathrm{M}$ 18-crown-6 and $0.2 \mathrm{M}$ $n$-bromophenacyl bromide were added to form FA conjugates. FA separation was performed on Agilent 1100 series HPLC with UV-Vis diode array detector. Linear gradient elution with $0.05 \mathrm{M}$ orthophosphoric acid and methanol on Agilent ZORBAX Eclipse XDB-C ${ }_{18} 5 \mu \mathrm{m}$ and Thermo Scientific Hypersil BDS, $\mathrm{C}_{18} 3 \mu \mathrm{m}$ reverse phase columns was used. Absorbance peaks corresponding to individual FAs were identified using standards.

Analysis of fluorescently-labelled products of phosphatidylcholine cleavage

Roots of B. napus plantlets were preincubated with $0.66 \mu \mathrm{g} \mathrm{ml}^{-1}$ boron-dipyrromethene (BODIPY) labelled phosphatidylcholine (BODIPY-2-decanoyl-1-(O-(11-(4,4difluoro-5,7-dimethyl-4-bora-3a,4a-diaza-s-indacene-3propionyl)amino)undecyl)-sn-glycero-3-phosphocholine, Invitrogen) for $10 \mathrm{~min}$ at $24{ }^{\circ} \mathrm{C}$ on an orbital shaker prior to treatment with reagents. At the end of the experiment lipids were extracted by the addition of methanol:chloroform 2:1 (v/v). Changes in the production of phospholipidderived second messengers were monitored using a thin layer chromatography (TLC). Unmodified silica gel 60 TLC plates (Merck) were developed with upper organic phase of the ethyl acetate/isooctane/formic acid/water (12:2:3:10, v/v) mixture. Lipid spots were visualized and counted by Pharos FX (Biorad) molecular imager. Products were identified according to Pejchar et al. (2010) and using standards.

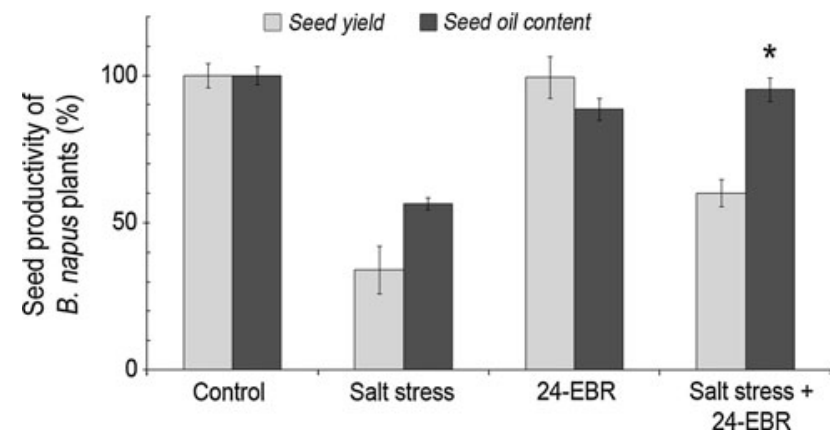

Fig. 2 Seed yield and seed oil content of Brassica napus cv. Magnat plants subjected to salt stress and 24-EBR. Plants were grown in soil substrate in individual containers. Salt stress was conditioned by adjusting soil $\mathrm{NaCl}$ concentration to $50 \mathrm{mM}$ by watering. Selected plants were treated with $100 \mathrm{nM}$ solution of 24-EBR by spraying during the course of germination and after 2 weeks of growth. At the end of plant vegetation, seeds were harvested, dried for 2 weeks and weighted. Seed oil was extracted from aliquot seed samples by solvents, evaporated and measured. Each seed aliquot was obtained from six plants grown in specified conditions. A statistical comparison (Student's $t$ test) was performed for data obtained from salt stressed-plants and salt stressed-plants treated by 24-EBR. Data represent the mean $\pm \mathrm{SE} ; *, P<0.05$, Student's $t$ test, $n=10$ discrete samples from two biological experiments

\section{Results and discussion}

24-Epibrassinolide application alleviates productivity loss in salt-stressed B. napus plants

Brassica napus are nowadays accounted to be the third most grown oil crop. We have analysed seed productivity and seed oil content of B. napus cv. Magnat plants under normal growth conditions and under salt stress. Plants were germinated and grown for 7 days. Then, a designated group of plants were watered with $\mathrm{NaCl}$ solution to achieve a final soil salt concentration of $50 \mathrm{mM} \mathrm{NaCl}$. Seeds were collected in dry siliques and weighted. The seed oil was extracted and assayed for quantity and quality. Our results indicate that seed productivity of $B$. napus was reduced by two thirds when cultivated in salt stress conditions. Oil content of seeds obtained from plants grown in salt conditions was also significantly decreased (Fig. 2), suggesting severe inhibition of lipid metabolic pathways.

It is well known that salt stress causes an inhibition of photosynthesis, of generic metabolism and of viability (Evers et al. 2012). Though it was shown that salt stress can trigger oil accumulation in growth-inhibited Chlamydomonas reinhardtii algae (Siaut et al. 2011), in case of oilseed plants its action is typically manifested by a dramatic loss of oil productivity (Francois 1994).

In contrast, BRs are known to enhance seed oil accumulation. For instance, end-point increase in oil content induced by tissue-specific photosynthesis in silique walls can be mimicked by application of BRs (Hua et al. 2012). 
In our studies, application of 24-EBR during germination and vegetative growth did not sizeably affected seed productivity or oil content of seeds obtained from control B. napus plants (Fig. 2). However, 24-EBR application restored the seed yield of salt-stressed plants to $60 \%$ of that of control plants. Besides, seed oil content in such conditions was matching that of normally-grown plants (Fig. 2).

This indicates a role for 24-EBR in modulating plant metabolic reactions, thus leading to alleviation of stress influence and increased plant productivity. Two explanations of the observed effect of 24-EBR should be considered. One possibility is that 24-EBR optimises plant growth and increase photosynthesis efficiency during stress. Another possibility is that exogenous BR treatment might subdue some of the plant basal activities or developmental programmes for sake of increased productivity. However, germination rate of seeds obtained from BR-treated plants was unaffected (data not shown). Being lipophilic compounds, BRs may also be targeted to membranes where they contribute to stress-induced adaptation.

Influence of salt stress and 24-EBR treatments on fatty acid composition of seed oil in B. napus and A. thaliana model plant

The FA composition of seed oil is a decisive factor of oil quality and usability both for biodiesel production and food purposes. We have analysed FA composition of seed oil from Arabidopsis model plants and B. napus crop plants belonging to the same Brassicaceae family (Fig. 3). FA compositions of seed oil obtained from both plant species were not significantly affected by $24-E B R$ treatment when grown in auspicious conditions. In turn, in the salt-stressed Arabidopsis, an increase in 16:0 and 18:1 FAs content was accompanied by the decrease in other FAs abundance (Fig. 3). In B. napus changes of FA composition induced by salt stress were less pronounced with the slight decrease of 18:1 and 16:1 FAs content notable (Fig. 3). Several plant hormones are known to affect lipid FA composition. Auxins increased FA polyusnaturation ratio in phosphatidylcholine, triglycerides and free fatty acids, but not in glycolipids in cotyledons of soybean embryo (Liu et al. 1995). Gibberellins had influence on the level of saturated FA in phospholipids of heat-shocked aleurone layers of barley (Grindstaff et al. 1996). In contrast, 24-EBR was previously reported to not influence FA composition in plant seeds (Janeczko et al. 2009). However, in another study, BRs affected FA profile of polar lipids in mango fruits resulting in higher unsaturation degree beneficial in cold stress conditions ( $\mathrm{Li}$ et al. 2012). We observed that 24-EBR application to plants subjected to salt stress have affected content of several FAs (Fig. 4). Hence, in the saltstressed B. napus 24-EBR treatment induced over-accumulation of 18:2 FA. In the salt-stressed Arabidopsis application of 24-EBR resulted in partial reversion of 18:1 and 20:1 FAs content to that of a control plants. This may possibly indicate weakening of stress impact in 24-EBRtreated plants, as also suggested by increased productivity (Fig. 1).

It is known that the relationship between fatty acid biosynthesis and stress responses is reciprocal in plants. As an example, FA desaturase was reported to be involved in salt tolerance in Arabidopsis (Zhang et al. 2012) and changes in FA composition were demonstrated to be critical for maintaining membrane properties and fluidity in

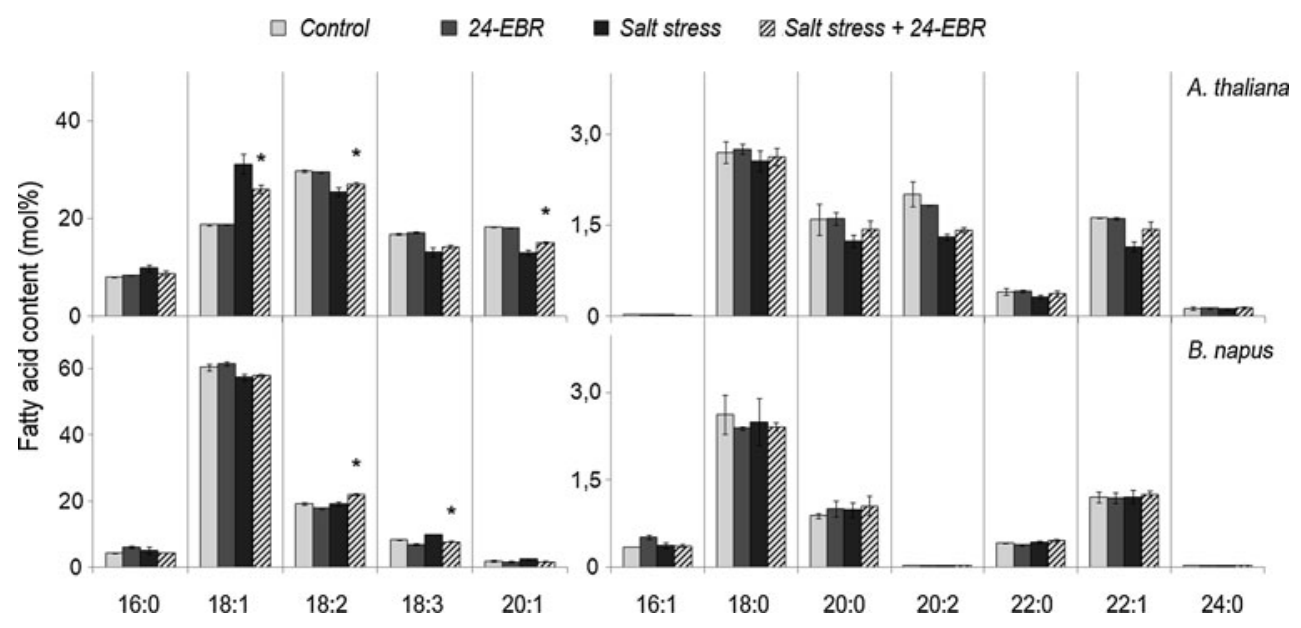

Fig. 3 Changes in fatty acid composition of seed oil from A. thaliana and $B$. napus subjected to different cultivation conditions. Oil samples were extracted from seeds gathered at the end of vegetative period and analysed by HPLC. Plant treatment conditions were identical to those described previously. A statistical comparison (Student's $t$ test) was performed for data obtained from salt-stressed plants and saltstressed plants treated by 24-EBR. Data represent mean $\pm \mathrm{SE}, n=3$; $*, P<0.05$, Student's $t$ test, $n=3$ discrete samples from two biological experiments 
(a)

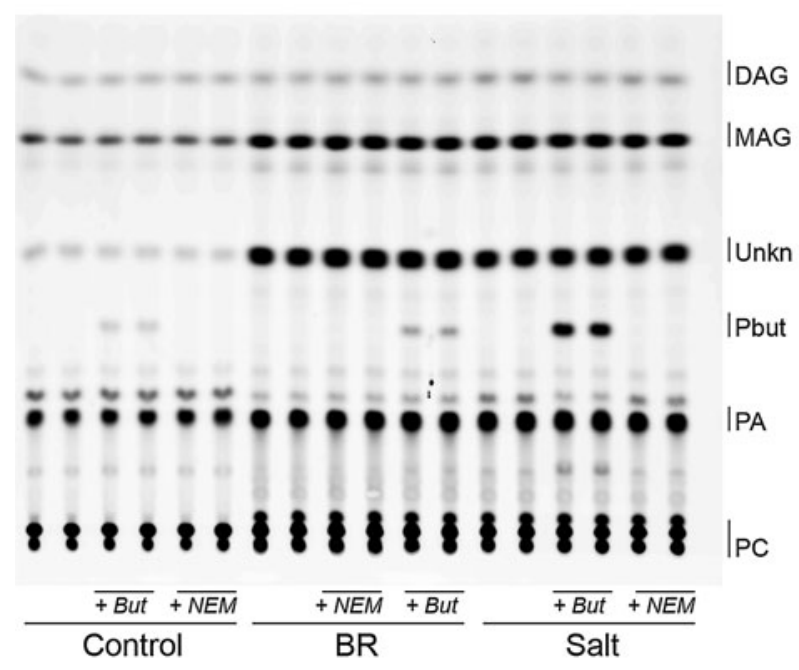

(b)
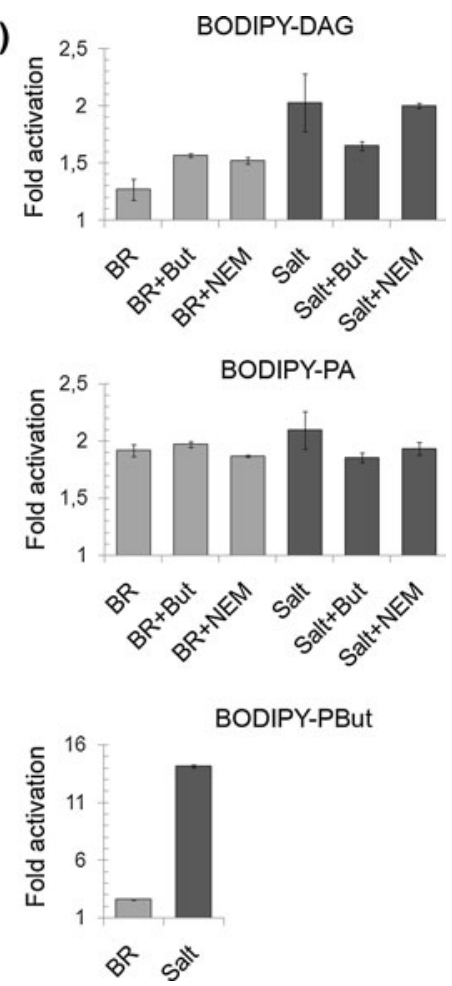

Fig. 4 Activation of phospholipid signalling in B. napus seedlings subjected to salt stress and 24-EBR. B. napus seedlings were hydroponically grown for 7 day. Seedlings were labelled with BODIPY-PC for $10 \mathrm{~min}$ and then $1 \mu \mathrm{M}$ 24-EBR (BR) or $100 \mathrm{mM}$ $\mathrm{NaCl}$ (Salt) were added as indicated. Control plants were treated with buffer. $N$-ethylmaleimide (NEM) and $n$-butanol (But) were added to the incubation buffer prior to stress treatment. After $2 \mathrm{~h}$ lipids were extracted and separated by TLC. a Chromatography plate.

stress conditions (Román et al. 2012). That is why the role of BRs in plant stress responses may be associated with adaptive changes of lipid FAs. Nevertheless, it should be noted that fatty acid composition of storage TAGs is usually distinct from that of membrane lipids.

Lipid signalling is activated by 24-EBR and upon salt stress in B. napus

Both abiotic and biotic stresses are known to evoke complex responses and defence reactions in plants (Atkinson and Urwin 2012). Here we investigated whether 24-EBR and stress conditions stimulate lipid signalling pathways in $B$. napus. Roots of 7-day-old plantlets were labelled with fluorescently labelled BODIPY-phosphatidylcholine for $10 \mathrm{~min}$ (Pejchar et al. 2010). Then $100 \mathrm{mM} \mathrm{NaCl}$ or $1 \mu \mathrm{M}$ 24-EBR were added in cultivation media for $2 \mathrm{~h}$ before extracting and separating lipids by thin layer chromatography (Fig. 4). Both treatments led to a substantial increase in fluorescent DAG and PA accumulation. This may suggest the activation of plant non-specific phospholipase $\mathrm{C}$ and/or phospholipase D enzymes that catalyse the hydrolysis of b Quantification of fluorescence associated with BODIPY-DAG, BODIPY-PA and BODIPY-PBut spots. The fluorescence was measured and expressed as fold change of that in control samples. Data represent mean $\pm \mathrm{SE}$ from independently analysed parallel samples $n=2$. DAG, diacylglycerol; MAG, monoacylglycerol; PA, phosphatidic acid; PC, phosphatidylcholine; Pbut, phosphatidylbutanol; Unkn, unknown product

phosphatidylcholine (PC) into DAG and PA, respectively (Hong et al. 2008; Kocourková et al. 2011; Krinke et al. 2009). In our experiments we have also studied the effects of two substances that affect lipid signalling. $N$-ethylmaleimide (NEM) is a thiol-reactive inhibitor of phosphatidate phosphatases that perform PA dephosphorylation to DAG (Furukawa-Stoffer et al. 1998). In turn, $n$-butanol (But) is used by PLDs as a substrate in the so-called transphosphatidylation reaction (Rainteau et al. 2012) thus leading to the production of phosphatidylbutanol (PBut) detrimentally to PA production. PBut production is thus considered as a marker of PLD activity (Kravets et al. 2010). In our investigations, we have observed limited or no effects of NEM on DAG and PA accumulation (Fig. 4). This indicates that DAG is likely to arise via a direct action of NPC on PC rather than via the dephosphorylation of PA. Treatment with $n$-butanol invoked slight decrease in PA production in salt stressed plants but not in plants treated with 24-EBR (Fig. 4). More importantly, these changes were markedly accompanied by the significant accumulation of PBut. To our knowledge, this is the first report demonstrating PLD activation in response to brassinosteroid treatment. Whether a post-translational 
activation of PLD or a regulation of PLD gene expression both contribute to the increased PLD activity in response to BRs is a question of further studies. It is also remain to be investigated whether BR treatment affects activity of diacylglycerol kinases that were identified as major contributors to PA production in plants (Arisz et al. 2013).

Lipid signalling is often regarded to be critical for plant stress-tolerance as was demonstrated for salt-sensitive PLD-deficient Arabidopsis mutants (Hong et al. 2008). Our results indicate that both $\mathrm{BR}$ and salt stress activate unidirectional lipid signalling. The way plant cell distinguish related signals evoked by dissimilar stimuli is not well understood. It is thought that spatial and temporal parameters of the second-messenger production by different phospholipases isozymes are important. Different composition of fatty acid residues in such signalling molecules may also stand for dissimilarity in evoked cellular responses (Maatta et al. 2012; Rainteau et al. 2012).

Plant lipid metabolism and oil accumulation is linked with $\mathrm{BR} /$ phospholipid signalling and plant stress responses

Here we provide an in silico analysis pointing at integration of plant lipid metabolism with BR/phospholipid signalling and stress responses at transcriptional level using Genevestigator interface (Hruz et al. 2008). Rapeseed genome has been reported to be sequenced by Bayer Crop science. However, the size and complexity of allotetraploid B. Napus genome and the lack of available array data make it challenging to conduct efficient in silico studies for this species. Instead, we have analysed gene expression data of the taxonomically related model plant $A$. thaliana (Fig. 5). Numerous genes that are involved in the lipid metabolism have their expression modified in response to BR and salt stress. As an example, KCS1 and $F A R 1$, genes encoding proteins implicated in FA biosynthesis, were identified to be BR-responsive (Goda et al. 2002). Interestingly, the expression of 3-KETOACYL-COA SYNTHASE 9 (KCS9), GLYCOSYLPHOSPHATIDYLINOSITOLANCHORED LIPID PROTEIN TRANSFER GENE 2 (LTPG2) and GDSL-LIKE LIPASE genes were repressed in salt stressed plants but activated after BR treatment. FATTY ACID REDUCTASE 1 (FARI) gene demonstrated reverse regulatory pattern. In addition two key genes of fatty acid metabolism FATA ACYL-ACP THIOESTERASE (FATA1) and FATTY ACID ELONGATION1 (FAEI) were affected by BR and salt stress unidirectional. These available data provide hints at putative targets of BR for controlling the lipid productivity in stress conditions.

BRs also affect the expression of several genes that are directly implicated in plant stress responses. Among them are $D R E B 2 A, R D 29 B$ and $R A B 18$. This may suggest that BRs can affect plant lipid productivity indirectly by boosting

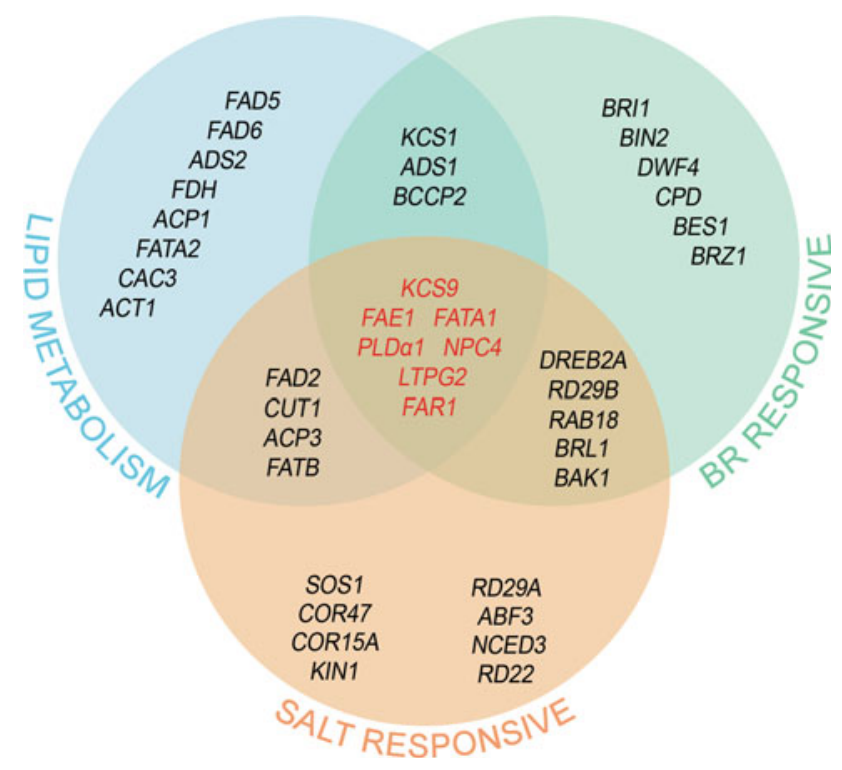

Fig. 5 Genetic association of lipid metabolism with BR-signalling and salt stress responses. Given here is a diagram representing $A$. thaliana genes implicated to lipid metabolism and signalling that show responsiveness to salinity conditions or treatment with brassinosteroids (as shown in circle intersections). Genes that potentially facilitate BR-mediated regulation of lipid metabolism in salt stress conditions are marked in red (Hruz et al. 2008). Common gene names are shown (for details see Electronic supplementary material Table 1). Experimental data used (GEO numbers): salt treatment AT-00120, brassinosteroid treatment AT-00110. Representative lipid metabolism genes were selected from (Beisson et al. 2003)

overall plant viability during stress (Clouse 2011). It was recently reported that expression of $D R E B 2 A$ is negatively regulated by the basal activities of phospholipase $\mathrm{D}$ and phospholipase C coupled to DGK (Djafi et al. 2013). This is an indication of the links between $D R E B 2 A$ genetic pathway and lipid signalling. This opens the possibility that BRs affect DREB2A expression through altering lipid signalling. In support, expression of several phospholipase genes (namely $P L D \alpha 1$ and NPC4) is also responsive to BRs and salt stress stimuli, which suggests their implication in the control of plant stress responses. Biochemical cues are also indicating that NPC activity is sensitive to BRs application in plants (Wimalasekera et al. 2010). It was also suggested that BRs act in concert with phospholipase $\mathrm{A}_{2}$-derived lysophosphatidylethanolamine phospholipid to regulate growth of primary roots and the formation of lateral roots in Arabidopsis (yoon Jeong et al. 2012).

The integration of phospholipases to lipid metabolism is now well ascertained. PA derived presumably from PC, as a major constituent of plant membranes, is important for lipid turnover and tobacco pollen tube growth (Pleskot et al. 2012). In turn, DAG molecules produced by NPC are common precursors to both membrane PC and storage TAGs (Pokotylo et al. 2013). Interestingly, phospholipases are abundant in seeds. PLD was shown to be active 
throughout most parts of seed development while germination and storage TAGs composition was significantly affected in PLD $\alpha$-deficient mutants of soybean (Lee et al. 2012). It is becoming apparent that not only phospholipases participate in immediate stress signalling but actively contribute to lipid turnover in plant leaves and, more importantly, seeds.

\section{Conclusions}

In summary, our results suggest that treatment of B. napus plants with BRs leads to the increased seed oil productivity in stress conditions. We have also observed that BRs and salt stress activate phospholipid signalling. This data suggest that phospholipases are among the cell components that mediate BRs signal. Gene expression analysis in publicly available database also provided a hint at an association of lipid metabolic processes with BRs and phospholipases. The question how BR signal is mediated downstream of lipid signalling implicating PLD and NPC phospholipases in plant cells is currently unanswered. Though some clues can be provided by the identification of DAG-sensitive or PA-sensitive intracellular targets (McLoughlin et al. 2013).

Not only our results provide evidences for BRs role in the control of lipid signalling and lipid metabolism, but they grant basis for further research required for steady development of biofuel production.

Acknowledgments We thank Institute of Agriculture NAAS for providing seeds of B. napus $\mathrm{cv}$. Magnat plants. We are also grateful to V.P. Grahov for the help with HPLC analysis. This work was supported by NAS of Ukraine (Grants No. 18-12 and No. 9.1-12).

\section{References}

Albrecht C, Boutrot F, Segonzac C, Schwessinger B, Gimenez-Ibanez S, Chinchilla D, Rathjen JP, de Vries SC, Zipfel C (2011) Brassinosteroids inhibit pathogen-associated molecular patterntriggered immune signaling independent of the receptor kinase BAK1. PNAS 109:303-308

Arisz SA, van Wijk Rv, Roels W, Zhu J-K, Haring MA, Munnik T (2013) Rapid phosphatidic acid accumulation in response to low temperature stress in Arabidopsis is generated through diacylglycerol kinase. Front Plant Sci 4(1). doi:10.3389/fpls.2013. 00001

Asghar HA, Zahir ZZ, Arshad MA, Khaliq AK (2002) Relationship between in vitro production of auxins by rhizobacteria and their growth-promoting activities in Brassica juncea L. Biol Fertil Soils 35(4):231-237

Atkinson NJ, Urwin PE (2012) The interaction of plant biotic and abiotic stresses: from genes to the field. J Exp Bot 63:3523-3543

Bates PD, Browse J (2012) The significance of different diacylglycerol synthesis pathways on plant oil composition and bioengineering. Front Plant Sci 3 (147). doi:10.3389/fpls.2012. 00147

Beisson F, Koo AJK, Ruuska S, Schwender J, Pollard M, Thelen JJ, Paddock T, Salas JJ, Savage L, Milcamps A, Mhaske VB, Cho Y, Ohlrogge JB (2003) Arabidopsis genes involved in acyl lipid metabolism. A 2003 census of the candidates, a study of the distribution of expressed sequence tags in organs, and a webbased database. Plant Physiol 132(2):681-697

Chapman KD, Ohlrogge JB (2012) Compartmentation of triacylglycerol accumulation in plants. J Biol Chem 287(4):2288-2294

Chaytor JP (1987) Analysis of fatty acids in lipids by high performance liquid chromatography (HPLC). Food Chem 23(1):19-27

Clouse SD (2011) Brassinosteroid signal transduction: from receptor kinase activation to transcriptional networks regulating plant development. Plant Cell Online 23(4):1219-1230

Divi U, Rahman T, Krishna P (2010) Brassinosteroid-mediated stress tolerance in arabidopsis shows interactions with abscisic acid, ethylene and salicylic acid pathways. BMC Plant Biol 10(1):1-14

Djafi N, Vergnolle C, Cantrel C, Wietrzynski W, Delage E, Cochet F, Puyaubert J, Soubigou-Taconnat L, Gey D, Collin S, Balzergue S, Zachowski A, Ruelland E (2013) The Arabidopsis DREB2 genetic pathway is constitutively repressed by basal phosphoinositidedependent phospholipase $\mathrm{C}$ coupled to diacylglycerol kinase in Arabidopsis thaliana. Front Plant Sci 4. doi:10.3389/fpls.2013. 00307

Evers D, Legay S, Lamoureux D, Hausman J, Hoffmann L, Renaut J (2012) Towards a synthetic view of potato cold and salt stress response by transcriptomic and proteomic analyses. Plant Mol Biol 78(4):503-514

Francois LE (1994) Growth, seed yield, and oil content of canola grown under saline conditions. Agron J 86(2):233-237

Furukawa-Stoffer TL, Byers SD, Hodges DM, Laroche A, Weselake RJ (1998) Identification of $N$-ethylmaleimide-sensitive and insensitive phosphatidate phosphatase activity in microsporederived cultures of oilseed rape. Plant Sci 131(2):139-147

Goda H, Shimada Y, Asami T, Fujioka S, Yoshida S (2002) Microarray analysis of brassinosteroid-regulated genes in Arabidopsis. Plant Physiol 130(3):1319-1334

Grindstaff KK, Fielding LA, Brodl MR (1996) Effect of gibberellin and heat shock on the lipid composition of endoplasmic reticulum in barley aleurone layers. Plant Physiol 110(2):571-581

Hong Y, Pan X, Welti R, Wang X (2008) Phospholipase D $\alpha 3$ is involved in the hyperosmotic response in Arabidopsis. The Plant Cell Online 20(3):803-816

Hruz T, Laule O, Szabo G, Wessendorp F, Bleuler S, Oertle L, Widmayer P, Gruissem W, Zimmermann P (2008) Genevestigator V3: a reference expression database for the meta-analysis of transcriptomes. Adv Bioinform 2008:420747

Hua W, Li R-J, Zhan G-M, Liu J, Li J, Wang X-F, Liu G-H, Wang H-Z (2012) Maternal control of seed oil content in Brassica napus: the role of silique wall photosynthesis. Plant J 69(3):432-444

Janda M, Planchais S, Djafi N, Martinec J, Burketova L, Valentova O, Zachowski A, Ruelland E (2013) Phosphoglycerolipids are master players in plant hormone signal transduction. Plant Cell Rep. doi:10.1007/s00299-013-1399-0

Janeczko A, Biesaga K, Cielniak J, Dziurka M (2009) 24-Epibrassinolide modifies seed composition in soybean, oilseed rape and wheat. Seed Sci Technol 37(3):625-639

Kagale S, Divi U, Krochko J, Keller W, Krishna P (2007) Brassinosteroid confers tolerance in Arabidopsis thaliana and Brassica napus to a range of abiotic stresses. Planta 225(2):353-364

Khripach V (1990) Synthesis of brassinosteroids. Pure Appl Chem 62(7):1319-1324

Kim T-W, Wang Z-Y (2010) Brassinosteroid signal transduction from receptor kinases to transcription factors. Annu Rev Plant Biol 61(1):681-704 
Kim T-W, Michniewicz M, Bergmann DC, Wang Z-Y (2012) Brassinosteroid regulates stomatal development by GSK3-mediated inhibition of a MAPK pathway. Nature 482(7385):419-422

Kocourková D, Krčková Z, Pejchar P, Veselková Š, Valentová O, Wimalasekera R, Scherer GFE, Martinec J (2011) The phosphatidylcholine-hydrolysing phospholipase C NPC4 plays a role in response of Arabidopsis roots to salt stress. J Exp Bot 62(11):3753-3763

Kravets VS, Kolesnikov YS, Kretynin SV, Getman IA, Romanov GA (2010) Rapid activation of specific phospholipase(s) D by cytokinin in Amaranthus assay system. Physiol Plant 138(3): 249-255

Krinke O, Flemr M, Vergnolle C, Collin S, Renou J-P, Taconnat L, Yu A, Burketová L, Valentová O, Zachowski A, Ruelland E (2009) Phospholipase D activation is an early component of the salicylic acid signalling pathway in Arabidopsis cell suspensions. Plant Physiol 150(1):424-436

Lee J, Welti R, Schapaugh WT, Trick HN (2011) Phospholipid and triacylglycerol profiles modified by PLD suppression in soybean seed. Plant Biotechnol J 9(3):359-372

Lee J, Welti R, Roth M, Schapaugh WT, Li J, Trick HN (2012) Enhanced seed viability and lipid compositional changes during natural ageing by suppressing phospholipase $\mathrm{D} \alpha$ in soybean seed. Plant Biotechnol J 10(2):164-173

Li M, Welti R, Wang X (2006) Quantitative profiling of Arabidopsis polar glycerolipids in response to phosphorus starvation. Roles of phospholipases $\mathrm{D} \zeta 1$ and $\mathrm{D} \zeta 2$ in phosphatidylcholine hydrolysis and digalactosyldiacylglycerol accumulation in phosphorus-starved plants. Plant Physiol 142(2): 750-761

Li B, Zhang C, Cao B, Qin G, Wang W, Tian S (2012) Brassinolide enhances cold stress tolerance of fruit by regulating plasma membrane proteins and lipids. Amino Acids 43(6):2469-2480

Liu W, Hildebrand DF, Collins GB (1995) Auxin-regulated changes of fatty acid content and composition in soybean zygotic embryo cotyledons. Plant Sci 106(1):31-42

Maatta S, Scheu B, Roth MR, Tamura P, Li M, Williams TD, Wang X, Welti R (2012) Levels of Arabidopsis thaliana leaf phosphatidic acids, phosphatidylserines, and most trienoate-containing polar lipid molecular species increase during the dark period of the diurnal cycle. Front Plant Sci 3 (49). doi:10.3389/fpls.2012.00049

McLoughlin F, Arisz SA, Dekker HL, Kramer G, de Koster CG, Haring MA, Munnik T, Testerink C (2013) Identification of novel candidate phosphatidic acid-binding proteins involved in the salt-stress response of Arabidopsis thaliana roots. Biochem J 450(3):573-581

Ohlrogge JB, Jaworski JG (1997) Regulation of fatty acid synthesis. Annu Rev Plant Physiol Plant Mol Biol 48(1):109-136

Pejchar P, Potocký M, Novotná Z, Veselková Š, Kocourková D, Valentová O, Schwarzerová K, Martinec J (2010) Aluminium ions inhibit the formation of diacylglycerol generated by phosphatidylcholine-hydrolysing phospholipase $\mathrm{C}$ in tobacco cells. New Phytol 188(1):150-160

Peng Y, Zhang J, Cao G, Xie Y, Liu X, Lu M, Wang G (2010) Overexpression of a $P L D \alpha 1$ gene from Setaria italica enhances the sensitivity of Arabidopsis to abscisic acid and improves its drought tolerance. Plant Cell Rep 29(7):793-802

Pleskot R, Pejchar P, Bezvoda R, Lichtscheidl IK, Wolters-Arts M, Marc J, Žárský V, Potocký M (2012) Turnover of phosphatidic acid through distinct signalling pathways affects multiple aspects of tobacco pollen tube tip growth. Front Plant Sci 3 (54). doi:10. 3389/fpls.2012.00054

Pokotylo I, Kretinin S, Kravets V (2012) Role of phospholipase D in metabolic reactions of transgenic tobacco caxl cells under the influence of salt stress. Cytol Genetics 46(3):131-135
Pokotylo I, Pejchar P, Potocký M, Kocourková D, Krčková Z, Ruelland E, Kravets V, Martinec J (2013) The plant non-specific phospholipase $\mathrm{C}$ gene family. Novel competitors in lipid signalling. Prog Lipid Res 52(1):62-79

Rainteau D, Humbert L, Delage E, Vergnolle C, Cantrel C, Maubert M-A, Lanfranchi S, Maldiney R, Collin S, Wolf C, Zachowski A, Ruelland E (2012) Acyl chains of phospholipase D transphosphatidylation products in Arabidopsis cells: a study using multiple reactions monitoring mass spectrometry. PLoS ONE 7(7):e41985

Román Á, Andreu V, Hernández ML, Lagunas B, Picorel R, Martínez-Rivas JM, Alfonso M (2012) Contribution of the different omega- 3 fatty acid desaturase genes to the cold response in soybean. J Exp Bot 63(13):4973-4982

Ruiz-López N, Sayanova O, Napier JA, Haslam RP (2012) Metabolic engineering of the omega-3 long chain polyunsaturated fatty acid biosynthetic pathway into transgenic plants. J Exp Bot 63(7): 2397-2410

Siaut M, Cuine S, Cagnon C, Fessler B, Nguyen M, Carrier P, Beyly A, Beisson F, Triantaphylides C, Li-Beisson Y, Peltier G (2011) Oil accumulation in the model green alga Chlamydomonas reinhardtii: characterization, variability between common laboratory strains and relationship with starch reserves. BMC Biotechnol 11(1):7

Sudriá C, Palazón J, Cusidó R, Bonfill M, Piñol MT, Morales C (2001) Effect of benzyladenine and indolebutyric acid on ultrastructure, glands formation, and essential oil accumulation in Lavandula dentata plantlets. Biol Plant 44(1):1-6

Tan H, Yang X, Zhang F, Zheng X, Qu C, Mu J, Fu F, Li J, Guan R, Zhang H, Wang G, Zuo J (2011) Enhanced seed oil production in canola by conditional expression of Brassica napus LEAFY COTYLEDON1 and LEC1-LIKE in developing seeds. Plant Physiol 156(3):1577-1588

Tang M, Guschina IA, O'Hara P, Slabas AR, Quant PA, Fawcett T, Harwood JL (2012) Metabolic control analysis of developing oilseed rape (Brassica napus cv Westar) embryos shows that lipid assembly exerts significant control over oil accumulation. New Phytol 196(2):414-426

Voelker T, Kinney AJ (2001) Variations in the biosynthesis of seed-storage lipids. Annu Rev Plant Physiol Plant Mol Biol 52(1):335-361

Wang G, Ryu S, Wang X (2012) Plant phospholipases: an overview. Lipases and phospholipases. In: Sandoval G (ed), vol 861. Methods in molecular biology. Humana Press, pp 123-137

Wimalasekera R, Pejchar P, Holk A, Martinec J, Scherer GFE (2010) Plant phosphatidylcholine-hydrolyzing phospholipases C NPC3 and NPC4 with roles in root development and brassinolide signaling in Arabidopsis thaliana. Mol Plant 3(3): $610-625$

Xia X-J, Huang L-F, Zhou Y-H, Mao W-H, Shi K, Wu J-X, Asami T, Chen Z, Yu J-Q (2009) Brassinosteroids promote photosynthesis and growth by enhancing activation of Rubisco and expression of photosynthetic genes in Cucumis sativus. Planta 230(6): 1185-1196

yoon Jeong S, Park C, Kim M-K, Jun Nam S, Hong J, Kim S-K (2012) Effect of lysophosphatidylethanolamine and brassinosteroids on development of Arabidopsis roots. J Plant Biol 55(2):178-184

Zhang Z, Ramirez J, Reboutier D, Brault M, Trouverie J, Pennarun A-M, Amiar Z, Biligui B, Galagovsky L, Rona J-P (2005) Brassinosteroids regulate plasma membrane anion channels in addition to proton pumps during expansion of Arabidopsis thaliana cells. Plant Cell Physiol 46(9):1494-1504

Zhang T, Song Y, Liu Y, Guo X, Zhu C, Wen F (2008) Overexpression of phospholipase $\mathrm{D} \alpha$ gene enhances drought and salt tolerance of Populus tomentosa. Chin Sci Bull 53(23):3656-3665 
Zhang A, Zhang J, Ye N, Cao J, Tan M, Zhang J, Jiang M (2010) ZmMPK5 is required for the NADPH oxidase-mediated selfpropagation of apoplastic $\mathrm{H}_{2} \mathrm{O}_{2}$ in brassinosteroid-induced antioxidant defence in leaves of maize. J Exp Bot 61(15):4399-4411
Zhang J, Liu H, Sun J, Li B, Zhu Q, Chen S, Zhang H (2012) Arabidopsis fatty acid desaturase FAD2 is required for salt tolerance during seed germination and early seedling growth. PLoS ONE 7(1):e30355 